\title{
Axonal Protein Synthesis and Degradation Are Necessary for Efficient Growth Cone Regeneration
}

\author{
Poonam Verma, ${ }^{1}$ Sabrina Chierzi, ${ }^{1}$ Amanda M. Codd, ${ }^{2}$ Douglas S. Campbell, ${ }^{3}$ Ronald L. Meyer, ${ }^{4}$ \\ Christine E. Holt, ${ }^{3}$ and James W. Fawcett ${ }^{1}$ \\ ${ }^{1}$ Cambridge University Centre for Brain Repair, Cambridge CB2 2PY, United Kingdom, ${ }^{2}$ University of California, San Francisco, San Francisco, California \\ 94143, ${ }^{3}$ Department of Anatomy, University of Cambridge, Cambridge CB2 3DY, United Kingdom, and ${ }^{4}$ Department of Developmental and Cell Biology, \\ University of California, Irvine, Irvine, California 92697
}

\begin{abstract}
Axonal regeneration can occur within hours of injury, the first step being the formation of a new growth cone. For sensory and retinal axons, regenerative ability in vivo correlates with the potential to form a new growth cone after axotomy in vitro. We show that this ability to regenerate a new growth cone depends on local protein synthesis and degradation within the axon. Axotomy in vitro leads to a fourfold to sixfold increase in ${ }^{3} \mathrm{H}$-leucine incorporation in both neurones and axons, starting within $10 \mathrm{~min}$ and peaking $1 \mathrm{~h}$ after axotomy. Application of protein synthesis inhibitors (cycloheximide and anisomycin) to cut axons, including axons whose cell bodies were removed, or proteasome inhibitors (lactacystin and $\mathrm{N}$-acetyl-Nor-Leu-Leu-Al) all result in a reduction in the proportion of transected axons able to reform growth cones. Similar inhibition of growth cone formation was observed on addition of target of rapamycin (TOR), p38 MAPK (mitogen-activated protein kinase), and caspase-3 inhibitors. Comparing retinal and sensory axons of different developmental stages, levels of ribosomal protein $\mathrm{P} 0$ and phosphorylated translation initiation factor are high in sensory axons, lower in embryonic axons, and absent in adult retinal axons. Conditioning lesions, which increase the regenerative ability of sensory axons, lead to increases in intra-axonal protein synthetic and degradative machinery both in vitro and in vivo. Collectively, these findings suggest that local protein synthesis and degradation, controlled by various TOR-, p38 MAPK-, and caspase-dependent pathways, underlie growth cone initiation after axotomy.
\end{abstract}

Key words: growth cone formation; axotomy; local protein synthesis; proteasome-mediated degradation; conditioning lesion; axon regeneration

\section{Introduction}

In contrast to peripheral nerves, damaged axons of the mammalian brain and spinal cord rarely regenerate. Although the nature of the neuronal environment, particularly inhibitory molecules on myelin and in glial scar tissue, can partially explain the lack of regeneration in the CNS, intrinsic neuronal factors also have an influence. Intrinsic influences on axon growth are neuronal age (Lagunowich et al., 1992; Li et al., 1995), neuronal cell type (Benfey et al., 1985; Rossi et al., 2001), distance of axotomy from the cell body (Fernandes et al., 1999), and conditioning (McQuarrie, 1978; Neumann and Woolf, 1999). Thus, embryonic axons grow through environments that ordinarily block regeneration, some axons mount a vigorous regenerative response whereas some never regenerate, axons cut close to the cell body show a greater regenerative response than those cut more distally, and axons may regenerate with greater vigor if they have been damaged some days previously.

\footnotetext{
Received March 15, 2004; revised Nov. 4, 2004; accepted Nov. 12, 2004

This work was funded by grants from Merck, Sharpe and Dohme, the Gates Foundation, the James Baird Fund, the Wellcome Trust, and the Medical Research Council.

Correspondence should be addressed to James Fawcett, Cambridge Centre for Brain Repair, E. D. Adrian Building,

Forvie Site, Robinson Way, Cambridge CB2 2PY, UK. E-mail: jf108@cam.ac.uk.

DOI:10.1523/JNEUROSCI.3073-04.2005

Copyright $\odot 2005$ Society for Neuroscience $\quad$ 0270-6474/05/250331-12\$15.00/0
}

For successful regeneration, the cut axon tip must first be remodeled to reform a new growth cone, a structure critical for subsequent axonal extension (Bray et al., 1978; Wessells et al., 1978; Ziv and Spira, 1998; Baas and Luo 2001; Spira et al., 2003). This transformation must involve major changes in the cytoskeleton and in membranous and cytoplasmic components. The earliest regenerative sprouting at the axon tip can occur within a day of axotomy (Friede and Bischhausen, 1980; Pan et al., 2003), too rapidly for the cell body to have been informed and to have synthesized and sent the necessary components, even by fast axonal transport. Indeed, even axons disconnected from their cell bodies in vitro can elaborate new growth cones at the site of lesion (Shaw and Bray, 1977; Baas et al., 1987), suggesting that most axons contain or are able to synthesize molecules needed for this process.

Evidence has accumulated indicating that axons can synthesize cytoskeletal proteins and contain specific mRNAs (OlinkCoux and Hollenbeck, 1996; Bassell et al., 1998; Eng et al., 1999; Koenig and Giuditta, 1999) and ribosomes (Bleher and Martin, 2001), and recent observations suggest that local protein synthesis within the axon is required for some axonal guidance events (Campbell and Holt, 2001) and may be involved in axon regeneration (Zheng et al., 2001; Hanz et al., 2003). Based on these observations, coupled to those suggesting a role for calpain- 
mediated protein degradation in growth cone regeneration (Spira et al., 2003), the present study examines the hypothesis that local protein synthesis and proteasome-mediated degradation are critical to the ability of an amputated axon to remodel its tip into a new growth cone. In previous studies, we demonstrated that for sensory and retinal axons, regenerative ability in vivo correlates with the potential to form a new growth cone after axotomy in vitro (Chierzi and Fawcett, 2001). Thus, sensory axons are almost always successful in regenerating their growth cones, whereas retinal axons are not. Moreover, with retinal axons, there is a developmental change, with embryonic axons having a greater ability to regenerate their growth cones than adult axons. In the present experiments, we extend these findings to demonstrate that local protein synthesis and degradation under the regulation of target of rapamycin (TOR), p38, and caspase- 3 signaling underlie the regeneration of a new growth cone after axotomy, that axotomized neurones and axons incorporate ${ }^{3} \mathrm{H}$ leucine, that axons with high regenerative ability have high levels of protein synthesis machinery, and that these levels increase after a conditioning lesion to peripheral nerves.

\section{Materials and Methods}

\section{Dorsal root ganglion cultures}

Dorsal root ganglion cells (DRGs) from embryonic (embryonic day 14 to embryonic day 15), postnatal (postnatal day 1 to postnatal day 2), and adult rats (Sprague Dawley) were collected using the following ageappropriate methods.

Embryonic rats $(n=50)$ were dissected in HBSS without calcium and magnesium (Invitrogen, San Diego, CA). Trimmed DRGs were plated whole on sterile glass coverslips that were precoated with $20 \mu \mathrm{g} / \mathrm{ml}$ polyD-lysine (Sigma-Aldrich, St. Louis, MO) and $5 \mu \mathrm{g} / \mathrm{ml}$ laminin (SigmaAldrich). Explants were maintained at $37^{\circ} \mathrm{C}$ in $160 \mu \mathrm{l}$ of growth medium [DMEM with $0.11 \mathrm{~g} / \mathrm{L}$ sodium pyruvate with pyroxidine (Invitrogen), 1:100 insulin-transferrin-selenium (ITS) (BD Biosciences, Franklin Lake, NJ), $2 \mu \mathrm{g} / \mathrm{ml} \mathrm{NGF} \mathrm{(Serotec,} \mathrm{Oxford,} \mathrm{UK),} \mathrm{1:100} \mathrm{penicillin-strep-}$ tomycin-fungizone (PSF) (Sigma-Aldrich] for $1 \mathrm{~d}$.

Postnatal rats $(n=50)$ were killed, and the DRGs were removed, plated, and cultured as detailed above.

Adult rats $(n=50)$ were killed. DRGs were trimmed and divided into smaller segments before plating and culturing as above.

\section{Retinal cultures}

Embryonic cultures were prepared from retinas of embryonic Sprague Dawley rats $(n=50)$ that were killed. Eyes were enucleated and collected in ice-cold HBSS (Invitrogen). Retinal tissue was separated from the pigment epithelium and sclera, and the blood vessels were carefully removed from the retinal surface. The tissue was mounted flat onto a Petri dish and cut into 200- $\mu \mathrm{m}$-thick squares on a McIlwain tissue chopper (Vibratome, Gorsham Surrey, UK). Retinal sections were then plated onto sterile plastic coverslips (Nunc, Roskilde, Denmark) that were pretreated with $667 \mu \mathrm{g} / \mathrm{ml}$ poly-D-lysine (Sigma-Aldrich) and $5 \mu \mathrm{g} / \mathrm{ml} \mathrm{lami-}$ nin (Sigma-Aldrich) and cultured for $5 \mathrm{~d}\left(37^{\circ} \mathrm{C}\right)$ in retinal growth medium (DMEM; Invitrogen) and Neurobasal A (Invitrogen) 1:1 supplemented with $\mathrm{N}_{2}$ (Invitrogen), sodium pyruvate (100 $\mu \mathrm{g} / \mathrm{ml}$; Invitrogen), glutamine ( $2 \mathrm{~mm}$; Invitrogen), T3-T4 (4 $\mu \mathrm{g} / \mathrm{ml}$; Sigma), glucose (1.1 mg/ml; Sigma), bovine serum albumin (76 $\mu \mathrm{g} / \mathrm{ml}$; Invitrogen), gentamycin (100 $\mu \mathrm{g} / \mathrm{ml}$; Invitrogen), and insulin ( $5 \mu \mathrm{g} / \mathrm{ml}$; Invitrogen).

Adult rats $(n=50)$ received a unilateral optic nerve crush $7 \mathrm{~d}$ before retinal dissection. The eyeball was subsequently removed, and an incision was made in the cornea allowing the lens to be removed. The retina was then separated from the sclera and cut radially, allowing it to lie flat. Retinal tissue was chopped, plated, and cultured as for embryonic explants.

Cultured samples were fixed in $-20^{\circ} \mathrm{C}$ methanol (100\%) for $3 \mathrm{~min}$, washed three times with PBS containing 10\% sodium azide (SigmaAldrich), and stored at $-4^{\circ} \mathrm{C}$.

\section{Growth cone formation assays}

Sensory and retinal explants were dissected as described above and plated onto four-well dishes (Nunc) that were precoated with $20 \mu \mathrm{g} / \mathrm{ml}$ poly-Dlysine (Sigma-Aldrich) and $5 \mu \mathrm{g} / \mathrm{ml} \mathrm{laminin} \mathrm{(Sigma-Aldrich)} \mathrm{for} \mathrm{sensory}$ explants and $667 \mu \mathrm{g} / \mathrm{ml}$ poly-D-lysine (Sigma-Aldrich) and $5 \mu \mathrm{g} / \mathrm{ml}$ laminin (Sigma-Aldrich) for retinal explants. Samples were maintained at $37^{\circ} \mathrm{C}$ for $2 \mathrm{~d}$ (DRGs) and $6 \mathrm{~d}$ (retina) in DRG and retinal growth medium, respectively. In control samples (no inhibitor), axons were axotomized with a pulled glass electrode, leaving a clear demarcation on the plastic substrate. Axons $(n=60)$ were photographed immediately and $4 \mathrm{~h}$ later to assess the degree of regeneration. From these measurements, the total number of regenerated axons was calculated. Experimental (inhibitor treated) samples were processed as detailed below.

Pharmacological agents for signaling pathway assays. For treated samples $(n=60$ per inhibitor), the protein synthesis inhibitors cycloheximide (25 $\mu \mathrm{M}$; Calbiochem, La Jolla, CA) and anisomycin ( $40 \mu \mathrm{M}$; Calbiochem) and the proteasome inhibitors lactacystin (10 $\mu \mathrm{M}$; Calbiochem) and $N$-acetyl-NorAl-Leucine-Leucine (LnLL) ( $50 \mu \mathrm{M}$; Calbiochem) were applied immediately before axotomy. Axons were then photographed, and the percentage of regenerating axons was calculated as for control samples.

Pharmacological agents for MAPK/caspase-3 assays. For signaling assays ( $n=60$ per inhibitor), the TOR inhibitor rapamycin (10 nM; Calbiochem) and the p38 MAPK (mitogen-activated protein kinase) inhibitor 4-(4-fluorophenyl)-2-(4-methylsulfonylphenyl)-5-(4-pyridyl)-1Himidazole (SB203580; $5 \mu \mathrm{M}$; Calbiochem) were applied immediately before axotomy. Similarly, for the caspase assays, the general caspase inhibitor caspase inhibitor 3 (CI3; $25 \mu \mathrm{M}$; Calbiochem), the caspase-3 inhibitor caspase-3 inhibitor 4 (C3I4; $20 \mu \mathrm{M}$; Calbiochem), and the caspase-9 inhibitor caspase-9 inhibitor 2 (C9I2; $25 \mu \mathrm{M}$; Calbiochem) were added to sensory and retinal cultures before axotomy. Axons were then photographed, and the percentage of regenerating axons was calculated as for control samples.

Isolated adult DRG axon-only cultures were also prepared. DRGs were cultured as above, and the cell body was surgically removed before the addition of control medium or inhibitor and axotomy.

\section{Time-lapse analysis}

All time-lapse analyses were performed using a digital camera (Nikon, Tokyo, Japan) and the Lucia Imaging Software (Nikon). Samples were cultured as above with the addition of 15 mM HEPES buffer (SigmaAldrich) to prevent $\mathrm{pH}$ fluctuations. Distal axonal segments from both nonaxotomized $(n=60)$ and axotomized $(n=60)$ axons were observed for $12 \mathrm{~h}$ under control (no inhibitor) and inhibitor-applied conditions to exclude the possibility of toxic effects of the inhibitors on the axons and to fully characterize axonal behavior under both control and experimental conditions.

\section{Measurement of protein synthesis in isolated axon cultures}

Protein synthesis in isolated axons from dorsal root ganglion cultures was detected by the incorporation of L- $\left[4,5-{ }^{3} \mathrm{H}\right]$-leucine (Amersham Biosciences, Arlington Heights, IL) into trichloroacetic acid (TCA)precipitated proteins (Campbell and Holt, 2001, 2003). Three equalsized pieces of adult dorsal root ganglia were plated on $20 \mu \mathrm{l} / \mathrm{ml}$ poly-Dlysine (Sigma-Aldrich) and $5 \mu \mathrm{g} / \mathrm{ml}$ laminin (Sigma-Aldrich)-coated coverslips and cultured at $37^{\circ} \mathrm{C}$ for $48 \mathrm{~h}$. Given the small amount of material, it was not feasible to measure the amount of protein. We therefore standardized the quantity of axotomized axon by placing the same number and size of DRG fragments into each culture and choosing for additional analysis only those cultures in which a similar size halo of axons surrounded each explant. Cultured axons were axotomized using a pulled glass capillary tube, and ${ }^{3} \mathrm{H}$-leucine incorporation rates were measured at 10, 20, $50 \mathrm{~min}, 1$, or $2 \mathrm{~h}$ after axotomy. Preparations with similar numbers of neurites were selected and transferred into leucine-free medium for $5 \mathrm{~min}$ before the addition of $\mathrm{L}-\left[4,5-{ }^{3} \mathrm{H}\right]$-leucine (specific activity, $138 \mathrm{Ci} / \mathrm{mmol})$. Ten minutes later, cultures were washed in leucinecontaining medium (60\% L15) (Invitrogen) and fixed with 25\% TCA for $30 \mathrm{~min}$. Measurements were made on cultures in which the DRGs were present, in which DRGs were removed before axotomy and ${ }^{3} \mathrm{H}$-leucine 
addition, in which the DRGs were removed after ${ }^{3} \mathrm{H}$-leucine incorporation but before TCA precipitation, and in which the TOR inhibitor rapamycin (10 nM; Calbiochem) and the p38 MAPK inhibitor SB203580 (5 $\mu \mathrm{M}$; Calbiochem) were applied before DRG removal, axotomy, and ${ }^{3} \mathrm{H}-$ leucine addition. One coverslip was inserted per vial, and radioactivity was measured with a scintillation counter. Each experimental time point was measured in triplicate, and the whole experiment was repeated twice. Control coverslips ( $\mathrm{L}-\left[4,5-{ }^{3} \mathrm{H}\right]$-leucine without axotomy) were included with each experimental condition.

\section{Conditioning nerve crush}

A unilateral sciatic nerve crush was performed in 200-300 g adult female Sprague Dawley rats $(n=20)$. Rats were killed 1 week later, and the lumbar DRGs (L3-L6) were removed from both preconditioned and control sides of the spinal cord. DRGs were either fixed (4\% paraformaldehyde) or cultured in $160 \mu \mathrm{l}$ of growth medium [DMEM with $0.11 \mathrm{~g} / \mathrm{L}$ sodium pyruvate with pyroxidine (Invitrogen), 1:100 ITS (BD Biosciences), $2 \mu \mathrm{g} / \mathrm{ml} \mathrm{NGF}$ (Serotec), 1:100 PSF (Sigma-Aldrich)] at $37^{\circ} \mathrm{C}$ for 1 or $4 \mathrm{~d}$.

Sciatic nerve from both preconditioned and control animals was also removed. After fixation ( $4 \%$ paraformaldehyde), both these and the fixed DRG samples were cryosectioned and stained.

\section{Immunohistochemical staining of cultures and tissue sections}

Fixed cultures and frozen sections $(6-10 \mu \mathrm{m}$ thick) obtained from fixed sciatic nerve, DRGs, and retina were blocked and incubated for $2 \mathrm{~h}$ in a humidified box with one of the following primary antibodies: antiphosphorylated translation initiation factor eIF-4E (phospho-eIF-4E) (Ser209) antibody (1:100; Cell Signaling Technology, Beverly, MA); antiribosomal protein P0 (ribosomal-P0) antibody (1:500; ImmunoVision, Springdale, AR); anti-ubiquitin (1:100; Calbiochem); FK2 antibody, which recognizes ubiquitin conjugated to proteins (1:100; Affiniti Research Products, Exeter, UK) (Fujimuro et al., 1994; Everett, 2000); and anti-20S proteasome "core" antibody (1:500; Affiniti Research Products). Cultures were subsequently washed three times in PBS/10\% sodium azide solution and incubated for $1 \mathrm{~h}$ with secondary antibodies conjugated to either cyanine 3 (1:100; Amersham) or FITC (1:100; Amersham). Antibody specificity was confirmed with Western blotting (supplementary Fig. S1, available at www.jneurosci.org as supplemental material). Immunoreactivity in cryosections was amplified with biotinylated tyramide (NEN, Boston, MA).

For the purposes of quantification, all samples were additionally double immunostained with the axonal markers $\beta$-3-tubulin (1:100; Sigma) or GAP-43 (1:100; gift from G. Wilkin, Imperial College, London, UK). Sections were double stained with 3A10 (1:5; Developmental Biology, Iowa City, IA) or anti-neurofilament-H (1:100; Affiniti Research Products). Samples were mounted on glass slides using Fluorosave (Calbiochem) and were allowed to set overnight.

\section{Quantification of immunofluorescence (cultures)}

Samples were analyzed by conventional fluorescence microscopy using a high-resolution digital camera (Nikon) and the Lucia Imaging Software (Nikon). Proximal axonal segments $(n=60)$ were selected based on their ability to be isolated from surrounding cells, and images were taken under a $60 \times$ objective. Quantitative measurements of immunofluorescence for anti-phospho-eIF-4E, anti-ribosomal-P0, anti-ubiquitin, antiproteasome core, and the FK2 antibody were performed on randomly selected samples of 60 segments of axons for each condition from at least five explants in each of three independent experiments. Standardized exposure times were established for each antibody for comparison between various developmental and axon types. Care was taken to avoid pixel saturation. Selected areas were traced with the software (Lucia; Nikon) by highlighting individual pixels until the entire area of interest was demarcated (supplementary Fig. S2a, available at www.jneurosci.org as supplemental material). The level of background fluorescence in adjacent areas of the selected samples was similarly calculated and subtracted from the proximal axon/growth cone value to give an antibody staining intensity value for the section of axon chosen. In addition, axonal staining from a negative control (no primary antibody) was measured as described above and subtracted from the intensity value gener- ated above to give a final intensity measurement. To ensure intensity values were attributable to real differences in antibody staining between axons rather than as a result of axonal dimensions, all intensities were calculated relative to the axonal marker $\beta$-3-tubulin and in the case of FK2, to GAP-43. Staining intensities for these markers were calculated as for the primary antibodies of interest and were consist regardless of axonal type and developmental stages and proximal-distal position along the axon (supplementary Fig. S2c, available at www.jneurosci.org as supplemental material). These two values were then divided by each other to generate a final intensity value relative to $\beta$-3-tubulin or GAP-43. Statistical analysis was performed using two- and four-way ANOVAs (SPSS version 11; SPSS, Chicago, IL). The pattern of values for the different types of axon generated using the above correction method was mirrored by those in which the intensity of the primary antigen alone was measured, although this data showed a greater variability within each axonal category (supplementary Fig. S2b, available at www.jneurosci.org as supplemental material).

\section{Quantification of immunofluorescence (sections)}

All quantification of axonal contents in DRG (20 sections in 20 individual nerves) and sciatic nerve sections ( 20 sections in 20 individual nerves) was performed on single confocal microscope images, taken at small aperture to ensure thin optical sections (Leica, Nussloch, Germany). Regions $\left(100 \mu \mathrm{m}^{2}\right)$ of conditioned and control sciatic nerve and dorsal root were selected for analysis. The sections were all stained with the $3 \mathrm{~A} 10$ or the neurofilament-H antibody to show the position of the axons and with one of the antibodies to the ribosomal protein P0, the phosphorylated translation initiation factor eIF-4E, proteasome core, ubiquitin, and ubiquitinated protein (FK2). The following three parameters were measured in axons for each antibody: (1) the proportion of identified axons that stained above background, (2) the length of each axonal profile was measured, and the length of axonal profile that was positive for each antibody stain, giving a proportion of total axon length positive for the stain, (3) the intensity of staining of the regions of axon that were positive for the antibody relative to the intensity of $3 \mathrm{~A} 10$ or in the case of FK2, neurofilament-H.

\section{Results}

\section{Growth cone regeneration in axotomized axons requires local protein synthesis and proteasome-mediated protein degradation}

\section{Regeneration of growth cones after axotomy}

To investigate whether intra-axonal protein synthesis and degradation play a part in growth cone dynamics and regeneration, we used the in vitro axotomy model used in our previous study ( $\mathrm{S}$. Chierzi and J. W. Fawcett, unpublished data). CNS and PNS axons at embryonic, newborn, and adult stages were grown on laminin, which promotes rapid axon growth from all these types of neuron. The neurons were then axotomized at a distance from the cell bodies with a pulled glass electrode, leaving a clear scratch on the plastic substrate. The assay therefore measures the regeneration of axons that have already demonstrated that they can grow on the laminin substratum. It tests the ability of axons to regenerate their growth cones when cut at a distance from the cell body and therefore regenerate from the cell body, whereas when first placed in culture, the axons are removed from the cell body and therefore regenerate from the cell-body field. Axons were photographed immediately and then analyzed $4 \mathrm{~h}$ later or recorded by time-lapse video microscopy. The axons were categorized into two classes: (1) regenerated axons, those that had reformed growth cones and elongated after axotomy and (2) "failed" axons, those that were unsuccessful in developing a growth cone and had not elongated (Fig. 1a). Video microscopy showed that in both DRG and retinal axons, axotomy was followed, usually within $5 \mathrm{~min}$, by the appearance of a terminal enlargement in the axon stump. This enlargement displayed os- 
cillatory behavior back and forth along the terminal portion of the axon. In some axons, this enlargement transformed into a new growth cone within $20 \mathrm{~min}$, whereas in others, it just continued to oscillate or retract. The ability of different axon types to regenerate their growth cones was the same as in our previous study. Thus, retinal ganglion cell axons had a low capacity to form new growth cones compared with DRG axons (Fig. 1b). In addition, developmental variation in the ability to form new growth cones after axotomy existed within both groups, with embryonic axons regenerating their growth cones more successfully than adult axons.

\section{Protein synthesis inhibitors block growth} cone regeneration

To determine whether the process of growth cone regeneration requires protein synthesis or proteasome-mediated protein degradation, we applied protein synthesis inhibitors $(25 \mu \mathrm{M}$ cycloheximide and 40 $\mu \mathrm{M}$ anisomycin) and proteasome inhibitors (10 $\mu \mathrm{M}$ lactacystin and $50 \mu \mathrm{M}$ LnLL). Treatment of cut axons with cycloheximide greatly inhibited growth cone regeneration in axons with high rates of regeneration such as embryonic sensory axons but had a proportionately lesser effect on axons that already have a low ability to regenerate and almost no effect on adult retinal axons. Similar results were obtained in adult DRG and retinal cultures with anisomycin. The treatments did not prevent the formation of terminal enlargements of the axon stump, but in the majority of cases, these swellings failed to progress to the formation of a new growth cone. The treatments did not simply postpone growth cone regeneration. Prolonged time analysis $(12 \mathrm{~h})$ was conducted on sensory and retinal axons that had failed to make new growth cones. Failed axons did not subsequently reform growth cones at a later stage, demonstrating that these inhibitors prevent growth cone reformation and regeneration rather than delaying it.

\section{Proteasome inhibitors block growth cone regeneration}

Application of the proteasome inhibitors lactacystin and LnLL to the preparations also resulted in a reduction in growth cone formation and axonal regeneration in sensory cell body preparations relative to controls. A much smaller reduction was seen in retinal axons. Axons from treated samples were able to develop terminal swellings.

\section{Lack of effect of treatments on control axons}

To test whether these compounds prevented axon growth per se or specifically prevented regeneration of growth cones on the end of cut axons, we observed their effects on the growth of control unsevered axons over the $4 \mathrm{~h}$ of our assays. Cultures were treated with cycloheximide and lactacystin, and axonal elongation was
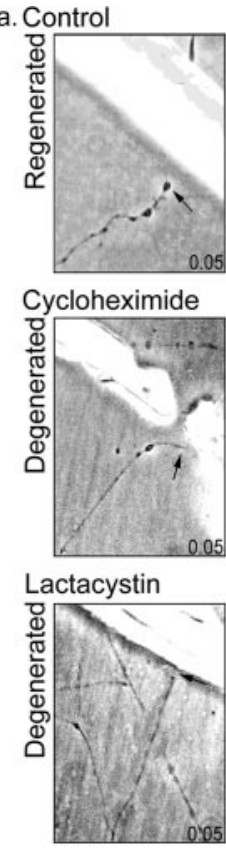
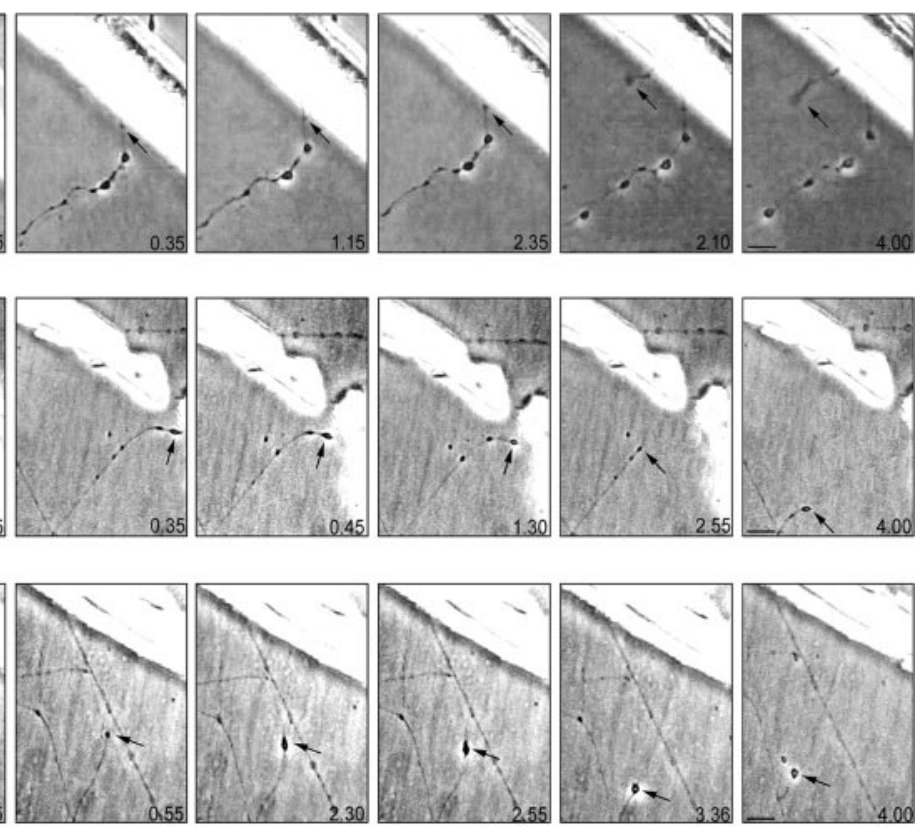

b. Effects of cycloheximide and lactacystin on growth cone regeneration

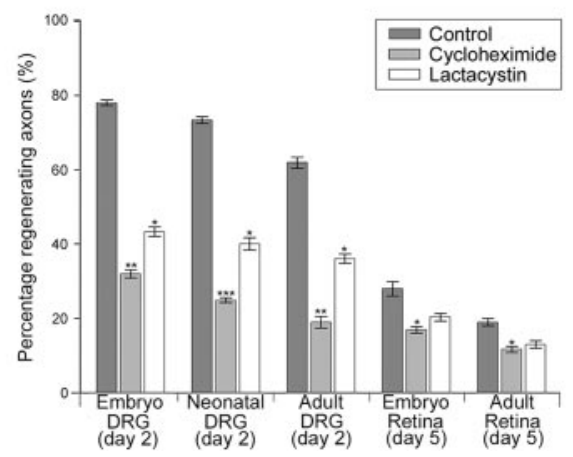

Figure 1. Effects of protein synthesis inhibitor cycloheximide $(25 \mu \mathrm{m})$ and proteasome-dependent degradative inhibitor lactacystin $(10 \mu \mathrm{m})$ on growth cone regeneration. $a$, Time-lapse images showing the typical responses of axons to axotomy and Axotomy was followed (within $5 \mathrm{~min}$ ) by the appearance of a terminal enlargement in the axon stump. This enlargement formed into a new growth cone in some axons, whereas in others, it continued to oscillate or retract. Scale bars, $10 \mu \mathrm{m} . b$ represents 60 axons. Error bars represent SEM. ANOVAs were calculated against the control for the relevant type of axon. ${ }^{*} p<$ $0.05 ;{ }^{* *} p<0.01 ;{ }^{* * *} p<0.001$

monitored. The proportion of axons whose growth cones progressed over this time was the same as in untreated preparations in both DRG (cycloheximide, $91 \pm 6 \%$; lactacystin, $89 \pm 5 \%$ ) and retinal (cycloheximide, $88 \pm 7 \%$; lactacystin, $90 \pm 4 \%$ ) cultures, indicating that axons were both alive and active.

Effects of protein synthesis inhibitors and proteasome inhibitors on regeneration of isolated axons

Because the axotomies were made 200-300 $\mu \mathrm{m}$ from the cell bodies, and growth cone regeneration, if it occurred, was generally observed within $30 \mathrm{~min}$, it was unlikely that new proteins produced in the cell body could have participated in growth cone regeneration. To confirm that intra-axonal protein synthesis and degradation are involved in growth cone formation, axotomy experiments were conducted with isolated axons from adult DRG explants (48 $\mathrm{h}$ in vitro). In this model, the entire ganglion was removed after cutting axons very close to it, leaving behind at least 
a. Effect of p38 and TOR inhibitors on growth cone regeneration

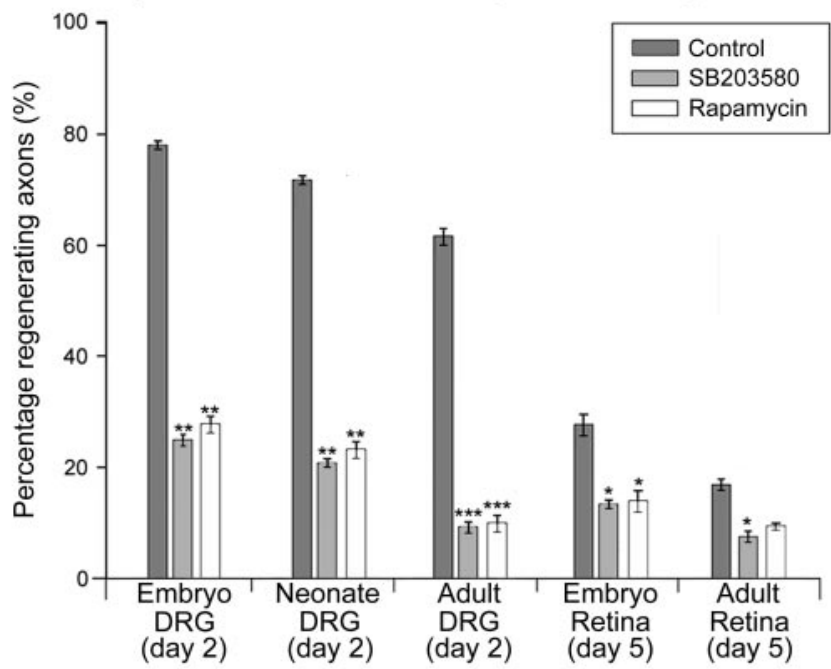

b. Effect of caspase inhibitors on growth cone regeneration

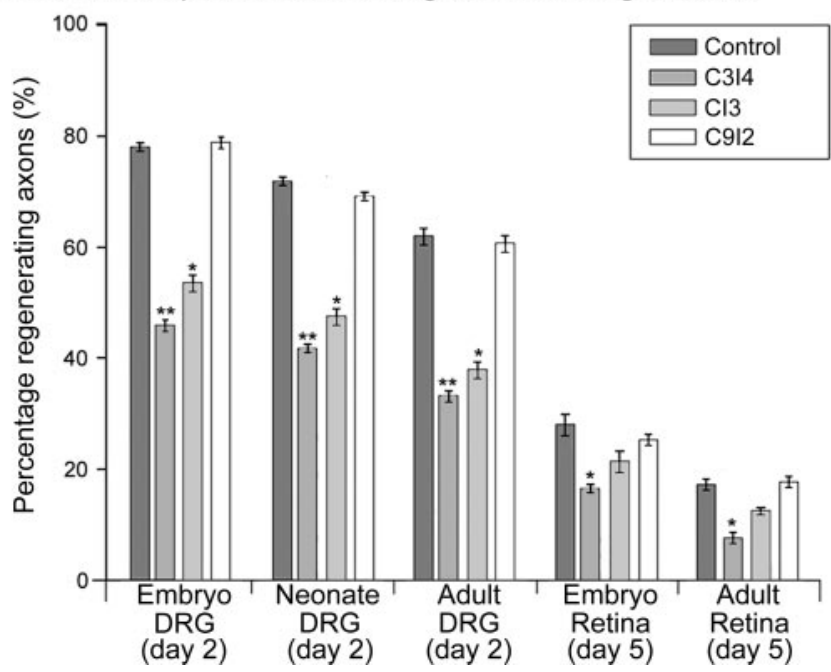

Figure 2. Effects of p38 MAPK (SB203580; $5 \mu \mathrm{M}), \mathrm{TOR}$ (rapamycin; $10 \mathrm{~nm})$, and caspase (Cl3, $25 \mu \mathrm{m} ;(3 \mid 4,20 \mu \mathrm{m} ;(9 \mid 2,25 \mu \mathrm{m})$ inhibitors on growth cone regeneration. $a$, Comparison of the percentage of regenerating axons from various types of axon after exposure to control-, SB203580-, and rapamycin-containing media. Data was collected by time-lapse analysis. $b$, Effects of the caspase-3 inhibitors $\mathrm{Cl} 3$ and $\mathrm{C} 314$. Each bar represents 60 axons. Error bars represent SEM. ANOVAs were calculated against the control for the relevant type of axon. ${ }^{*} p<0.05$; ${ }^{* *} p<0.01 ;{ }^{* * *} p<0.001$.

$500 \mu \mathrm{m}$ of axon. After this, the axons remained morphologically intact for at least $5 \mathrm{~h}$, and their growth cones continued to be motile and to advance. When these isolated axons were cut close to their distal end, the proportion that were able to form new growth cones was almost identical to that seen for axons still attached to their cell bodies. Inhibitors were then applied immediately after removal of the cell body and just before axotomy. For both protein synthesis and proteasome inhibitors, the effect on the proportion of regenerating axons in the axon-only preparations was the same as for the preparations with the cell bodies still attached (supplementary Fig. S3a, available at www.jneurosci.org as supplemental material).

TOR, p38 MAPK, and caspase-3 inhibition reduces growth cone formation and regeneration in axotomized axons In view of the preceding evidence of a requirement for local protein synthesis and degradation in growth cone formation, we a. Incorporation of ${ }^{3} \mathrm{H}$-leucine into axotomised and non-axotomised (control) cell-body attached adult DRG cultures

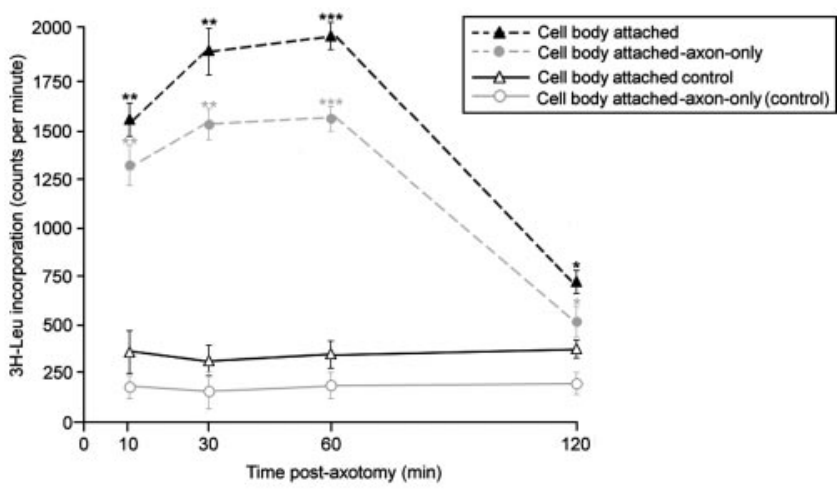

b. Incorporation of ${ }^{3} \mathrm{H}$-leucine into axotomised and non-axotomised (control)

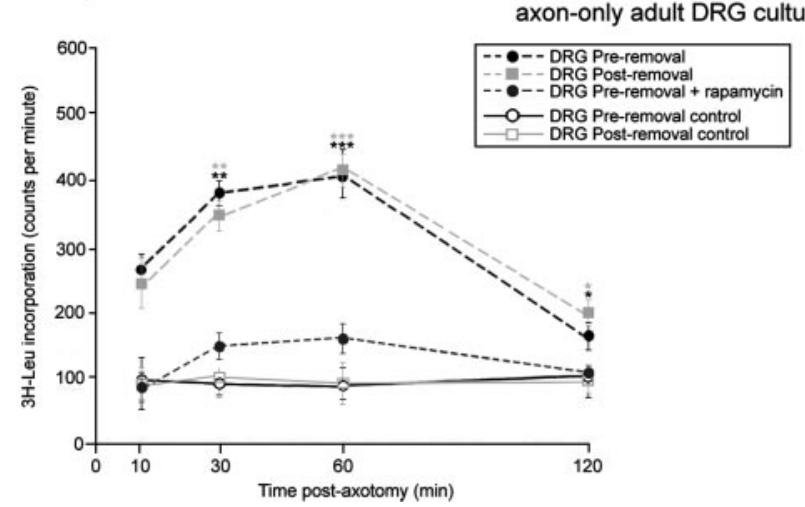

Figure 3. Axotomy results in an increase in ${ }^{3} \mathrm{H}$-leucine incorporation in neurones and isolated axons. $a$, Incorporation of TCA-precipitated ${ }^{3} \mathrm{H}$-leucine into adult DRG cultures in which axons and DRGs were both present (Incorporation into the cell body alone was calculated by subtraction of neuronal incorporation from incorporation into isolated axons.). $b$, Incorporation of ${ }^{3} \mathrm{H}$-leucine into isolated DRG axons. DRGs were either removed before axotomy and ${ }^{3} \mathrm{H}-$ leucine addition (preremoval) or after ${ }^{3} \mathrm{H}$-leucine incorporation but before TCA precipitation (postremoval). The TOR inhibitor rapamycin (10 nm) was also applied to samples before DRG removal, axotomy, and ${ }^{3} \mathrm{H}$-leucine addition. Error bars represent SEM. ANOVAs were calculated against the nonaxotomized control for each time point. $n=6$; ${ }^{*} p<0.05$; ${ }^{* *} p<0.01$; ${ }^{* * *} p<$ 0.001

have examined the possible role of various signaling pathways in this process.

Inhibitors of TOR and $p 38$

As a first step to the identification of potential upstream regulators of growth cone regeneration, we focused on TOR, the mitogen-activated protein kinase p38, and caspase-3, molecules highly expressed in the CNS and implicated in recent studies on the regulation of axonal protein synthesis during axon guidance (Campbell and Holt, 2001, 2003). The reagents used in this study were identical to those in these previous papers. Using the in vitro axotomy model as above, CNS and PNS axons at embryonic, newborn, and adult stages were grown, axotomized, and scored for successful or failed regeneration. When the p38 inhibitor SB203580 was added immediately before axotomy, the percentage of axons, particularly sensory axons, that regenerated growth cones after axotomy was significantly diminished (Fig. 2a). Growth cone formation was also inhibited in retinal cultures, although to a lesser extent. Application of the TOR inhibitor rapamycin resulted in similar diminutions of growth cone regeneration; these were less pronounced, however, than with 
SB208530. These experiments were repeated on axons that had been disconnected from their cell bodies, as in the previous section (supplementary Fig. S3b, available at www.jneurosci.org as supplemental material). Inhibitors were applied immediately after removal of the cell body and just before axotomy. For both the TOR and p38 inhibitors, the effect on the proportion of regenerating axons in the axon-only preparations was almost exactly the same as in the preparations with the cell bodies still attached. We next investigated whether inhibition of both p38 and TOR simultaneously would produce an additive effect. When rapamycin and SB203580 were added together, we observed a greater reduction in the number of axons forming growth cones than was seen with either treatment alone (supplementary Fig. S3b, available at www.jneurosci. org as supplemental material). Neither the TOR nor the p38 inhibitors had any significant effect on the elongation of axons in control cultures without axotomy $(4 \mathrm{~h})$.

\section{Caspase inhibitors}

Caspase targets include actin and actin binding proteins, suggesting a possible mechanism by which caspases could mediate growth cone reformation. Significantly, caspases can act downstream of p38, prompting us to question whether they could be involved in growth cone formation. In vitro growth cone formation after axotomy was reduced in both complete (cell body attached) (Fig. 2b) and isolated sensory and retinal axons (supplementary Fig. S3c, available at www.jneurosci.org as supplemental material) on application of the general caspase inhibitor caspase- 3 inhibitor $\mathrm{CI} 3$ and by the specific caspase-3inhibitor C3I4 but not by an inhibitor of caspase-9, C9I2. Proportionately the greatest effect was seen on sensory axons.

Axotomy-induced increases in L-[4,5$\left.{ }^{3} \mathrm{H}\right]$-leucine incorporation occur in cellbody attached and isolated dorsal root ganglion axons

To measure changes in protein synthesis directly, ${ }^{3} \mathrm{H}$-leucine incorporation was measured in axon-only cultures and cultures in which the axons were still connected to their cell bodies at various times after axotomy (Campbell and Holt., 2001, 2003). After axotomy, there was an increase in ${ }^{3} \mathrm{H}$-leucine incorporation, beginning by $10 \mathrm{~min}$ and peaking after $1 \mathrm{~h}$. The increases at $1 \mathrm{~h}$ were fivefold to sixfold (cell body attached) and fourfold to fivefold (axon only), with increases both in axonal and cell body incorporation (Fig. 3). Two types of assay for axonal incorporation were performed: in the first, the DRGs were removed before axotomy and ${ }^{3} \mathrm{H}$-leucine

e. a. Ribosomal-P0 b. Axonal variations in ribosomal-P0 immunoreactivity
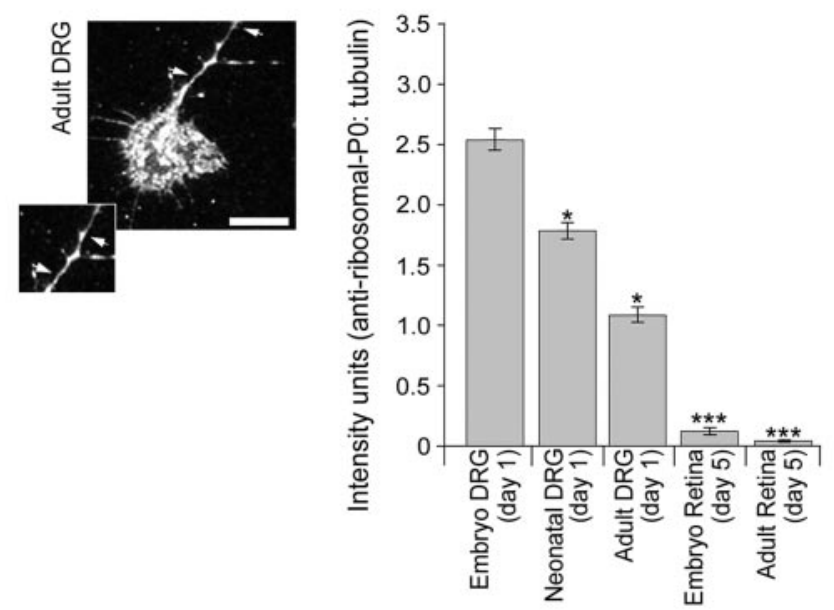

c. Phospho-elF 4E

d. Axonal variations in phospho-elF 4E immunoreactivity
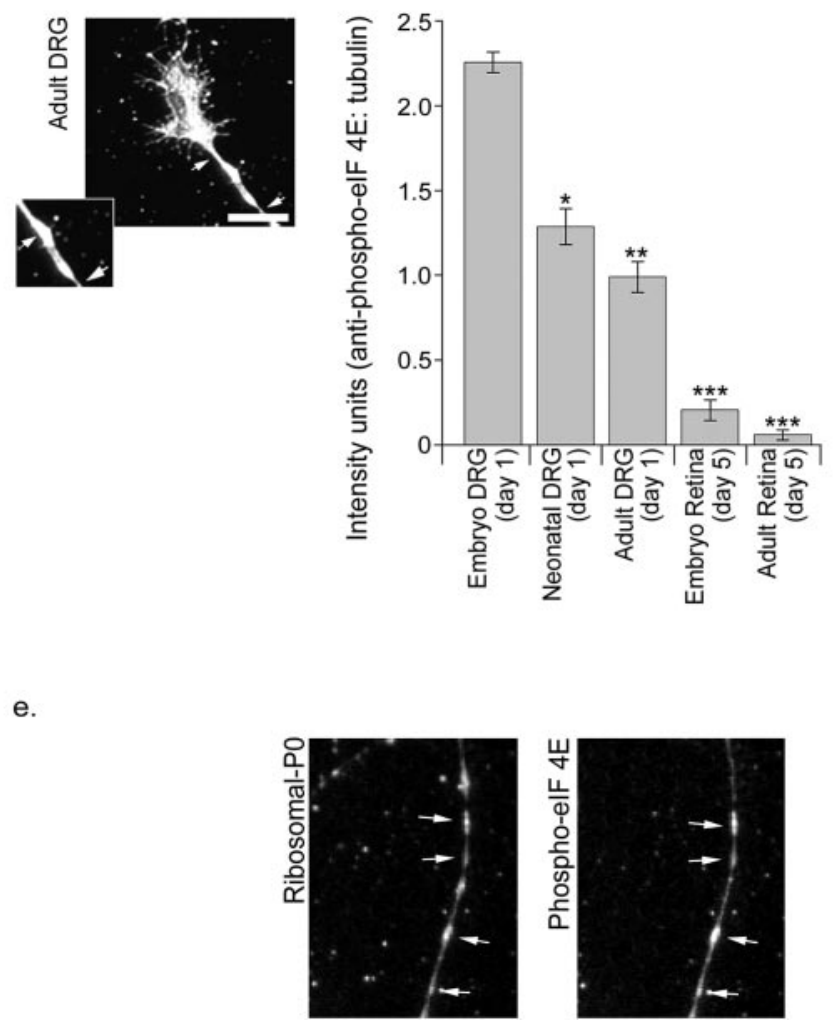

Figure 4. Distribution of protein synthetic machinery (ribosomal-P0, phospho-elF-4E) in sensory and retinal axons. Fluorescence imaging demonstrating punctate staining for ribosomal-P0 ( $a$, insert, arrows) and phospho-elF-4E ( $c$, insert, arrows) and their colocalization $(e)$ in adult DRG axons. Immunofluorescence intensities were measured for selected regions of axon (section between arrows in $a$ and $c$; scale bars, $10 \mu \mathrm{m}$ ). $b, d$, Quantification of fluorescence intensities for ribosomal-PO ( $b$ ) and phosphoelF-4E $(d)$ relative to $\beta$-tubulin for sensory and retinal axons of various developmental stages. Comparable relative levels of staining were obtained without correction with $\beta$-tubulin, although variances were more marked (Fig. S2, available at www. jneurosci.org as supplemental material). Each bar represents data collected from 60 axons. Error bars represent SEM. ANOVAs were calculated relative to the immunostaining intensity for embryonic DRG samples. ${ }^{*} p<0.05 ;{ }^{* *} p<0.01$; ${ }^{* * *} p<0.001$. addition, and in second, the DRGs were removed after ${ }^{3} \mathrm{H}$ leucine incorporation but before TCA precipitation. These two assays gave identical results. In general, at all time points after axotomy, ${ }^{3} \mathrm{H}$-leucine incorporation in the cell-body was approximately four times greater than in the axons alone. Application of the TOR inhibitor rapamycin to axon-only samples resulted in a 
a. 20s proteasome "core" b. Axonal variations in anti-proteasome "core" immunoreactivity
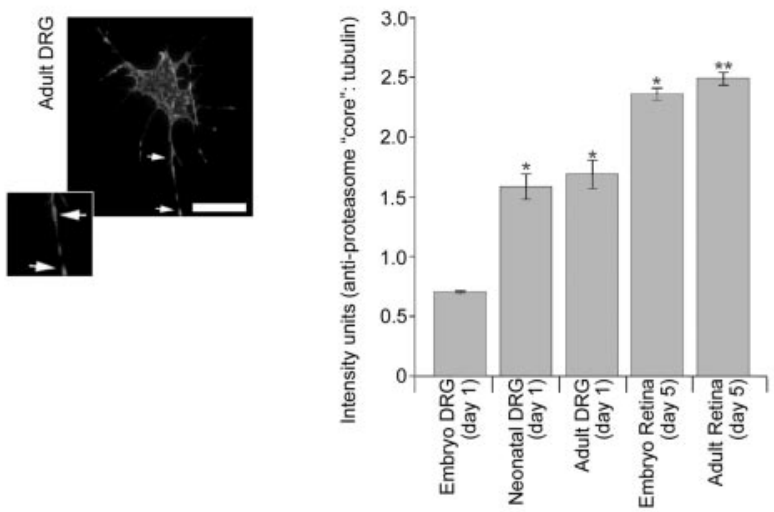

c. Ubiquitin

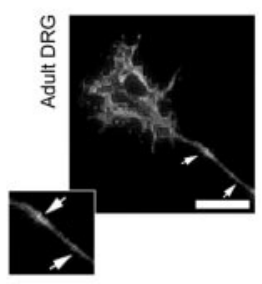

d. Axonal variations in ubiquitin immunoreactivity

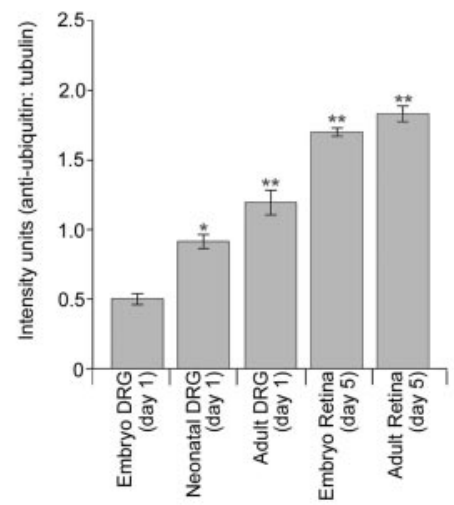

e. Ubiquitinated protein

f.Axonal variations in ubiquitinated protein immunoreactivity
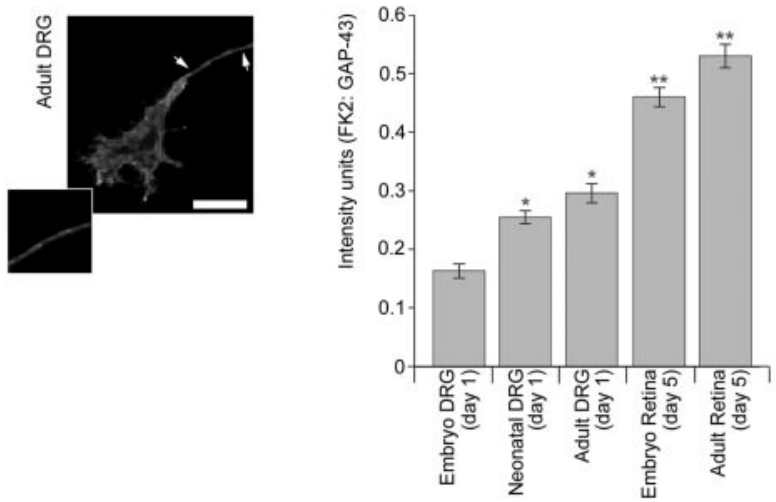

g.

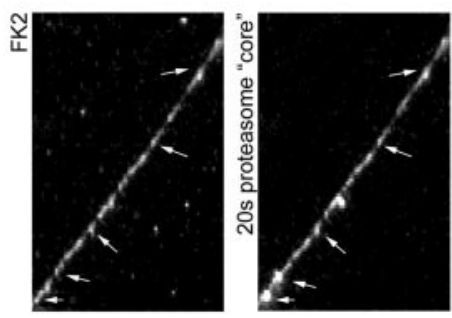

Figure 5. Distribution of protein degradative machinery (20S proteasome core, ubiquitin, and ubiquitinated protein) in sensory and retinal axons. Analysis of axons revealed granular staining for 205 proteasome core $(a)$ and ubiquitinated protein $(e)$; adult DRG axons are shown. In contrast, ubiquitin staining ( c) was smooth. Immunofluorescence intensities for all three antigens were measured for selected regions of axon (section between arrows in $a, c, e$; scale bars, $10 \mu \mathrm{m}$ ). Quantification of fluorescence intensities for 205 proteasome core $(b)$, ubiquitin $(d)$, and ubiquitinated protein $(f$ relative to $\beta$-tubulin for sensory and retinal axons of various developmental stages. Comparable relative levels of staining were obtained without correction with $\beta$-tubulin, although variances were more marked. Each bar represents data collected from 60 axons. Error bars represent SEM. ANOVAs were calculated relative to the immunostaining intensity for embryonic DRG samples. ${ }^{*} p<0.05$; ${ }^{* *} p<0.01 . g$, Colocalization of 205 proteasome core and ubiquitinated protein. Scale bars, $10 \mu \mathrm{m}$. significant reduction in the incorporation of ${ }^{3} \mathrm{H}$-leucine after axotomy, with a less than twofold peak increase (Fig. 3b). Similar results were obtained with the p38 inhibitor SB203580.

Protein synthetic machinery is present at higher levels in dorsal root ganglion axons than in retinal ganglion cell axons The preceding experiments demonstrate that for sensory and retinal axons, regenerative ability in vivo correlates with the capacity to form a new growth cone after axotomy in vitro. They also show that protein synthesis and to a lesser extent proteasome-mediated proteolysis are involved in growth cone regeneration. We therefore examined whether these different axonal regenerative capabilities correlate with axonal levels of translational and degradative machinery.

The level and distribution of ribosomal-P0 protein and the phosphorylated translation initiation factor eIF-4E were analyzed in embryonic, postnatal, and adult sensory and retinal axons cultured in vitro (Fig. 4). Explants were double stained with the primary antibody of interest, anti-ribosomal-P0 or phospho-eIF-4E, and the axonal marker $\beta$-3-tubulin. Intensity measurements from a defined region of axon were recorded on a scale of 0 to 256 for both the primary antibody and tubulin (supplementary Fig. S2a, available at www.jneurosci.org as supplemental material). In initial experiments, these raw data were analyzed. In subsequent experiments, these values were then ratioed to give the intensity of immunoreactivity relative to $\beta$-3-tubulin, giving an effective correction for axon diameter. This correction did not change the differences that we saw between the levels of different molecules in the various axon types, but it reduced the variance (Fig. S2b, available at www. jneurosci.org as supplemental material).

All our results are presented as the brightness of the immunofluorescence relative to $\beta$-3-tubulin. $\beta$-3-Tubulin was chosen because its immunofluorescence is constant along the length of axons and reflects axon diameter (Fig. S2c, available at www.jneurosci.org as supplemental material). The intensity of $\beta$-3-tubulin immunoreactivity was not significantly different between the different types and ages of axon, although thicker axons obviously gave a brighter signal than thinner axons. Thus, if the $\beta$-3-tubulin intensity was 50 , and the intensity of the other antigen was 100 , we would report the staining intensity as +2 intensity units. Antigens with staining dimmer than $\beta$-3-tubulin would give values below 1 intensity unit. 
There was bright immunofluorescence for phospho-eIF-4E along the entire length of sensory axons, in particular in less mature axons (Fig. $4 c, d$ ). In comparison, immunoreactivity of adult and embryonic retinal axons was significantly less than that observed in dorsal root ganglion axons. Similar but more pronounced results were observed for ribosomal-P0, with sensory axons containing high levels, embryonic retinal axons low levels, and ribosomal-P0 being almost absent in adult retina (Fig. $4 a, b$ ). Whereas the pattern of staining for $\beta$-3-tubulin was even along the axon length, staining with antiribosomal-P0 or phospho-eIF-4E antibodies gave a granular appearance. Double staining for anti-ribosomal-P0 and phospho-eIF-4E revealed frequent regions of colocalization (Fig. 4e).

\section{Proteasome-mediated protein}

degradative machinery is present at higher levels in retinal axons than in dorsal root ganglion axons

To characterize the levels of proteasomemediated protein degradative machinery in axons of the dorsal root ganglion and retinal axons, we used antibodies to the proteasome core (Fig. 5a,b), ubiquitin (Fig. $5 c, d$ ), and an antibody against ubiquitinated-protein conjugates, FK2 (Fig. 5e,f). Measurements were taken relative to $\beta$-3-tubulin (anti-proteasome core, anti-ubiquitin) and GAP-43 (FK2). Although all axons stained brightly with these antibodies, higher levels of all three antigens were detected in embryonic and adult retinal axons compared with embryonic, neonatal, and adult sensory axons.

Staining with both the FK2 and the anti-proteasome core antibody was granular. On additional analysis, these two antigens were found to colocalize in the axon (Fig. $5 g$ ). Ubiquitin, however, appeared homogeneously dispersed along the axon.

Protein synthetic machinery increases and proteasome-mediated protein degradative machinery decreases in response to a conditioning lesion

A previous (conditioning) lesion of a peripheral nerve can lead to enhanced axonal regeneration after a subsequent lesion. Adult DRGs from animals that had received a sciatic nerve crush 1 week previously were cultured, and the axons were analyzed after 1 and $4 \mathrm{~d}$ in vitro (Fig. 6). Axons growing from conditioned DRGs showed higher immunoreactivity for ribosomal-P0 and the phosphorylated translation initiation factor eIF-4E compared with controls (Fig. $6 a, b)$. In con-
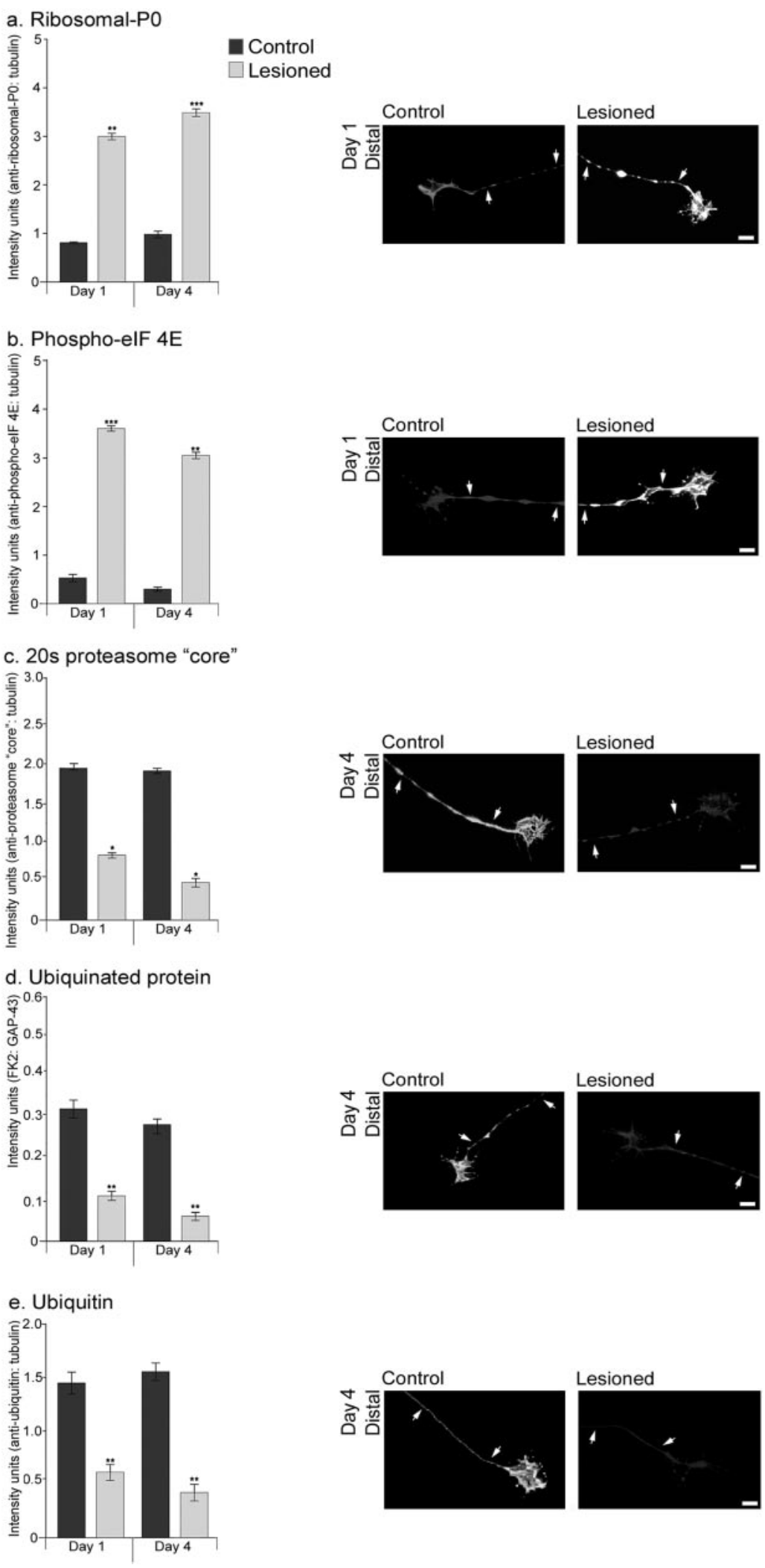

Figure 6. Immunoreactivity for protein synthesis machinery increases, whereas that for protein degradative machinery decreases in adult DRG axons placed in vitro after a conditioning lesion. The DRGs were placed in culture $7 \mathrm{~d}$ after a sciatic nerve crush and then maintained for 1 or $4 \mathrm{~d}$. $a$, Ribosomal-P0; $b$, phospho-elF-4E; $c$, 20 S proteasome core; $d$, ubiquitinated protein; $e$, ubiquitin. For all antigens, quantification of immunofluorescence was calculated relative to $\beta$-tubulin; however, the comparative levels were the same without correction although with greater variance. Immunofluorescence intensities for both antigens were measured for selected regions of axon (section between arrows). Lower exposure times were chosen than for previous quantifications to avoid pixel saturation. Scale bars, $10 \mu \mathrm{m}$. Each bar represents data collected from 60 axons. Error bars represent SEM. ${ }^{*} p<0.05$; ${ }^{* *} p<0.01$; ${ }^{* * *} p<0.001$. 

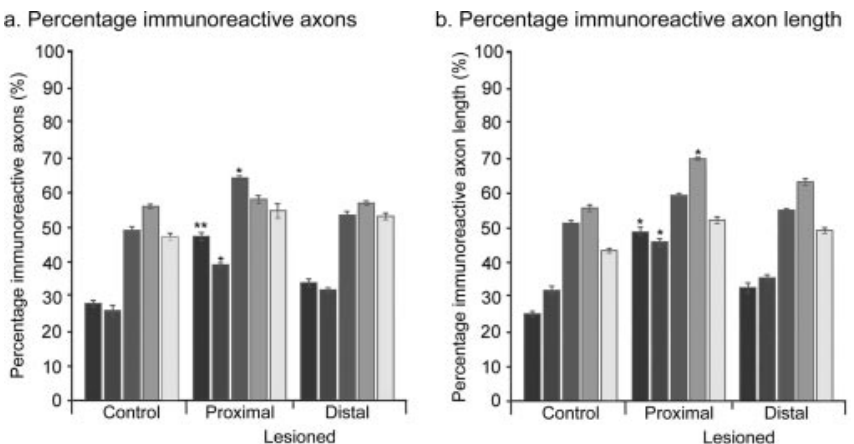

c. Axonal immunoreactive intensities

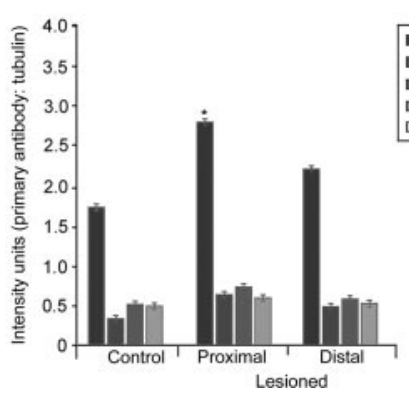

Figure 7. The effects of the conditioning lesion on the in vivo expression of axonal protein synthetic and degradative machinery within the sciatic nerve, measured just proximal and distal to a nerve crush. $a$, The percentage of positive axon profiles; $b$, the percentage of total axonal length that was positive; $c$, the intensity of immunoreactivity in positive regions. Each bar represents data collected from 20 sections from 20 individual nerves. Error bars represent SEM. ${ }^{*} p<0.05 ;{ }^{* *} p<0.01$.

trast, these axons stained more dimly for proteasome core, ubiquitin, and ubiquitinated-protein conjugates (Fig. $6 c, d, e$ ). This pattern was evident regardless of the length of time the explant spent in vitro ( 1 or $4 \mathrm{~d})$.

\section{The conditioning lesion results in in vivo changes in axonal protein synthetic and degradative machinery}

We next measured whether the above in vitro changes after a conditioning lesion were reflected in vivo. Cryosections of sciatic nerve (conditioned and control) and DRGs (conditioned and control) were analyzed by laser-scanning confocal microscopy, all of the analysis being done on single thin optical sections. We examined sciatic nerves just proximal and distal to the crush site and the central and peripheral nerve trunks attached to DRGs.

Axonal immunoreactivity was quantified by three parameters, the proportion of neurofilament or $3 \mathrm{~A} 10$ positive axonal profiles that were positive for the antigen, the proportion of total axonal length within the section that displayed immunoreactivity, and the intensity of intra-axonal staining, where it was present.

\section{Control nerves}

We examined sciatic nerve and the central and peripheral branches attached to DRGs. In control unlesioned sciatic nerve, ribosomal-P0 and the phosphorylated translation initiation factor eIF-4E were present in a proportion of axonal profiles and absent in others. Where a length of axon could be followed, the immunoreactivity was in patches. Axon profiles therefore tended to be either strongly immunoreactive or unstained. We could not follow individual axons along their entire length, so we cannot say whether any axons were negative along their whole length. Immunoreactivity for degradation machinery antigens (proteasome core and ubiquitinated protein) was again patchy, but a larger proportion of axons were positive and a greater proportion of total axonal length was immunoreactive than was the case for ribosomes or phosphorylated translation initiation factor. In the nerve trunks of DRGs, there was a similar pattern of staining to sciatic nerve (see Fig. $8 a-e$ ). Immunoreactivity for all antigens was discontinuous along the axon length. However, the proportion of axons that were immunoreactive and the proportion of total axon length that was positive was greater than for the region of sciatic nerve $0.5 \mathrm{~cm}$ distal to the spine and where the lesions were made (Figs. 7, 8).

\section{Lesion-conditioned nerves}

Seven days after a conditioning lesion, for all antigens there was a small increase in the proportion of immunoreactive axonal profiles in sciatic nerve and the percentage of axon length that was immunoreactive proximal to the lesion site (Fig. $7 a, b)$. There was also an increase in the staining intensity of ribosomal-P0 staining in conditioned axons compared with control axons (Fig. 7c). In the DRGs, there was enhancement of all five antigens both in the peripheral and central nerve branch, as assessed by the proportion of axons and length of labeled axon (Fig. $8 a-e, g-i$ ). The intensity of ribosomal-P0 staining was increased in the central and peripheral branches (Fig. $8 a-e$ ).

\section{Adult retina}

We examined ribosomal-P0 and proteasome core immunoreactivity in the adult retina and optic nerve (Fig. $8 f$ ). Ribosomal-P0 staining was very bright in retinal ganglion cells and was also present in the axon initial segment between the cell body and the axon bundles on the retinal surface. However, no ribosomal-P0 staining was observed in axons in the retinal bundles or in the optic nerve. In contrast, staining for proteasome core was intense in both retinal axon bundles and in the optic nerve.

\section{Discussion}

Regenerating mammalian axons are tipped by a growth cone, and failure to make a new growth cone after axotomy would therefore make an axon unable to regenerate (Shaw and Bray., 1977; Bray et al., 1978; Wessells et al., 1978; Ziv and Spira 1998; Baas and Luo 2001; Spira et al., 2003). The experiments reported here and previous work (Chierzi and Fawcett, 2001, unpublished data) suggest that those axons with poor regenerative potential in vivo are poor at regenerating their growth cones after axotomy. Growth cone regeneration shares some features with the sprouting of collateral branches, a process characterized by the formation of new growth cones in parts of the axons in which growth processes have ceased, and this process is dependent on major cytoskeletal transformations at sprouting sites (Gallo and Letourneau, 1999; Dent and Kalil, 2001). The majority of proteins constituting the growth cone ultrastructure, notably actin, neurofilaments, and mitochondria, travel down the axon by "slow" axonal transport (actin at $2-4 \mathrm{~mm} / \mathrm{d}$ and neurofilaments at $0.25 \mathrm{~mm} / \mathrm{d}$ ) from the cell body (Black and Lasek, 1979, 1980). Assuming similar components are required by severed axons, even those proteins carried by the fastest axonal transport $(300 \mathrm{~mm} / \mathrm{d})$ will take days to reach the site of many nerve injuries. Most clinical injuries occur at some distance from the cell body, yet axonal regeneration may begin as rapidly as $1 \mathrm{~d}$ after injury (Friede and Bischhausen, 1980; Pan et al., 2003). This, coupled to observations that growth cone regeneration in sensory and retinal axons in vitro can occur even when axons are surgically isolated from their cell bodies, suggests that the first steps in regeneration do not have to await the arrival of new proteins from the cell body (Aguayo et al., 1973; Shaw and Bray, 1977; Baas et al., 1987). However, axonal transport is in- 
a.

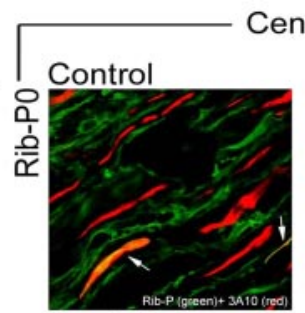

b.

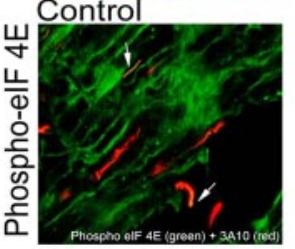

c.

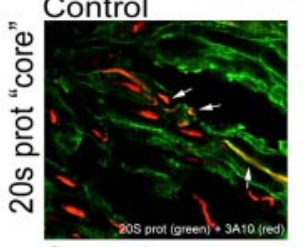

d.

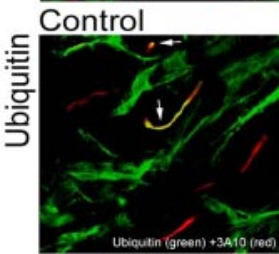

e.

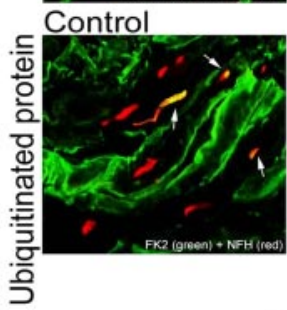

g. Percentage immunoreactive axons

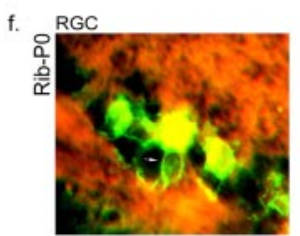

h. Percentage immunoreactive axon

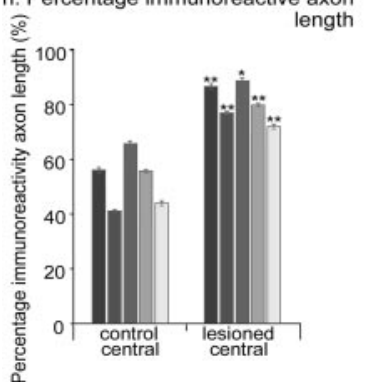

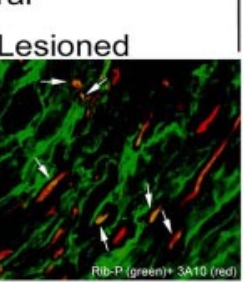

Lesioned
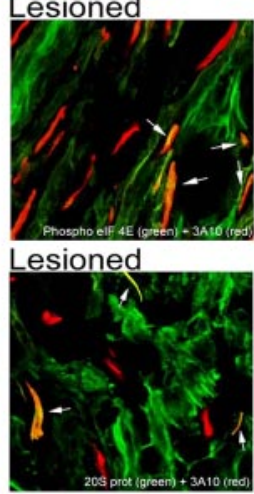

Lesioned

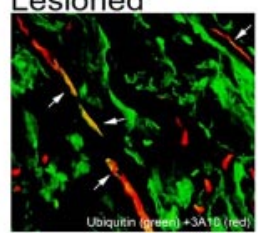

Lesioned
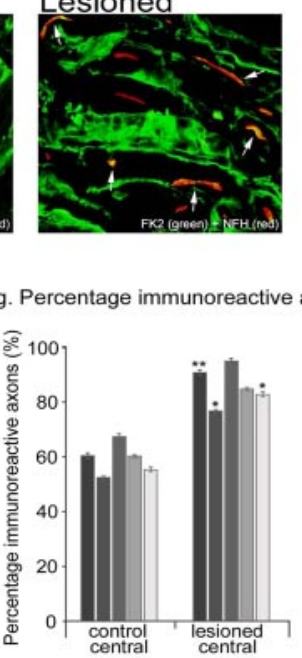

i. Axonal immunoreactive axon intensities

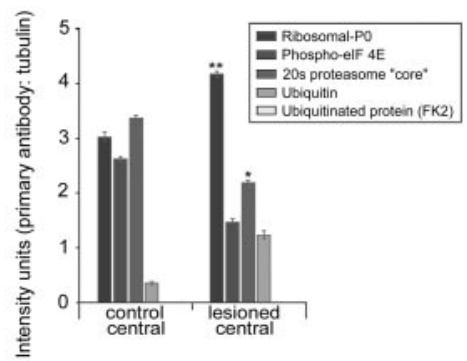

Figure 8. Effects of the conditioning lesion on the in vivo levels and distribution of axonal protein synthetic and degradative machinery within the central dorsal root nerve attached to dorsal root ganglia. Sections were immunostained for the antigen of choice (green) and an axonal marker [3A10, neurofilament-H (red)]. $a$-e are single thin optical sections. Immunohistochemistry revealed that both control and conditioned adult DRG axons contain protein synthetic (ribosomal-P0, phospho-elF-4E) ( $a, b$, arrows) and degradative machinery (20S protea-

creased after axotomy, and new proteins from the cell body will arrive in time to support continuing axon regeneration.

\section{Local protein synthesis and proteasome-mediated protein degradation is involved in growth cone regeneration} The changes necessary for growth cone regeneration could be accomplished by the redistribution of existing proteins (Hollenbeck and Bray, 1987) or by synthesis of new proteins at the injury site. Various studies have identified elements of the protein synthetic pathway namely ribosomes and cytoskeletal mRNAs ( $\beta$ actin, tubulin, tau) in developing vertebrate peripheral and central axons, in synapses, in growth cones of embryonic and neonatal axons, and recently in adult sensory axons (Olink-Coux et al., 1996; Bassell et al., 1998; Eng et al., 1999; Koenig and Giuditta., 1999; Bleher and Martin., 2001; Zheng et al., 2001; Hanz et al., 2003), and there is also evidence for the involvement of axonal protein synthesis in guidance (Campbell and Holt, 2001; Zheng et al., 2001; Brittis et al., 2002) and calpain in growth cone dynamics (Spira et al., 2003), introducing another possibility, that intra-axonal protein synthesis and degradation might be involved in growth cone regeneration. Our experiments provide direct evidence for this hypothesis. Axotomy leads to a large increase in the incorporation of ${ }^{3} \mathrm{H}$-leucine in both axotomized axons and neurones. We applied the translational inhibitors to axotomized axons in vitro and found that growth cone regeneration was greatly reduced in sensory axons, whereas in retinal axons, which have an intrinsically low regenerative ability, there was little change. There is also a need for local proteasomemediated protein degradation, because proteasome inhibitors reduce the proportion of transected sensory axons that form growth cones. These effects were on the axon rather the cell body, because the same effects were seen when the cell bodies were surgically removed before the experiment, and because the axotomies were too far away from the cell body for axonal transport to have delivered new cell body-produced proteins to the growth cones by the time they initiated regeneration. These treatments have little or no effect on uncut axons that are already growing over the time course of our assays, and it is therefore specifically the remodeling of the cut axon tip that requires new proteins.

\section{The role of TOR, p38 MAPK, and caspases in growth cone regeneration}

Translation of mRNAs after axotomy must be regulated, and previous studies provide some insight into the signaling pathways that might be involved (Rehder et al., 1992; Goldberg and Wu, 1995). TOR, p38, and caspase-3, highly expressed in the CNS, are implicated in the mediation of neurite outgrowth (Perron and Bixby, 1999), growth cone turning (Campbell and Holt, 2003), and resensitization (Forcet et al., 2002; Ming et al., 2002), and critically, through the phosphorylation of transcription factors, protein synthesis (Gingras et al., 1999). In the current study, we suggest a novel role for TOR, p38 MAPK, and caspase-3 in growth cone formation. Pathways, such as the TOR-dependent

some core, ubiquitin, and ubiquinated protein) ( $(-e$, arrows). Quantification of the percentage of axon profiles that were positive $(g)$, the percentage of total axonal length that was positive $(h)$, and the intensity of staining of positive regions ( $i$ ) for the various antigens. Each bar represents data collected from 20 sections from 20 individual nerves. Error bars represent SEM. ${ }^{*} p<0.05$; ${ }^{* *} p<0.01$. Scale bar, $10 \mu \mathrm{m}$. $f$, In adult retina, ribosomal-P0 (green) was present in retinal ganglion cells and the axon initial segment where it joined a bundle of axons coursing across the retinal surface (arrow); staining was absent in the axons already in the bundle. Conversely, staining for proteasome core was intense in the retinal axon bundles. 
phosphatidyl inositol-3 kinase, can initiate sprouting (Gallo and Letourneau, 1998) and may regulate translation via eIF-4EBP1 and eIF-4E48 (Dardevet et al., 1996; Mendez et al., 1996; Sonenberg and Gringras, 1998). MAPKs have many potential targets in neurons (Grewal et al., 1999), including regulation of translation via the phosphorylation of the translational repressor eIF-4EBP and via the translational activator eIF-4E (Gingras et al., 1999; Herbert et al., 2002). In addition, our data provide evidence for the role of caspase- 3 as a potential mediator of growth cone reformation. Other degradative pathways rely on extracellular calcium, which is needed for growth cone regeneration in Aplysia sensory axons (Gitler and Spira, 1998) and mammalian sympathetic, sensory, and retinal neurons (Chierzi and Fawcett, unpublished data) (Kulbatski et al., 2004).

\section{Levels of synthetic machinery correlate with growth cone regeneration ability}

In vivo, axons differ in their regenerative capacity depending on neuronal type (Benfey et al., 1985; Rossi et al., 2001) and age (Li et al., 1995; Shewan et al., 2002). Even when presented with an optimal environment, many CNS axons fail to regenerate. Thus, after peripheral nerve grafts to the transected optic nerve, only a small proportion of those RGC axons whose cell bodies survive axotomy will regenerate (Vidal-Sanz et al., 1987), and similar poor regenerative ability is seen in the Purkinje cells of the cerebellum and in rubrospinal axons (Rossi et al., 1995, 2001; Tetzlaff et al., 1994). Intrinsic regenerative ability both in vivo and in vitro decreases with development (Bates and Meyer, 1997; Goldberg et al., 2002). In a previous experiment (Chierzi and Fawcett, 2001), confirmed here, we have shown that in sensory and retinal axons, these differences in regenerative ability in vivo correlate with the ability of axons to regenerate their growth cones after axotomy in vitro. The assay used in these experiments specifically tests the regenerative ability of axons cut at a distance from the cell body, rather than the ability of axons to grow out from an axotomized cell body, and the axons cut in these experiments have already demonstrated that they are able to grow on the laminin substrate.

Given that axonal protein synthesis and degradation is necessary for growth cone regeneration, axons with good regenerative abilities might have high levels of protein synthesis machinery, and axons with poor regenerative abilities might have little ability to synthesize new proteins. Our results support such a correlation both in vivo and in vitro, with the axons that possess the greatest regenerative potential in vivo containing more translational machinery, and axons with poor regenerative potential containing less. In particular, adult retinal axons had undetectable levels of ribosomal-P0 both in vitro and in vivo, whereas levels in sensory axons of all ages were high. All the axons contained considerable levels of proteasome-mediated degradative machinery, although the poorly regenerating axons had higher levels. Levels of $20 \mathrm{~S}$ proteasome core, ubiquitin, and ubiquitinated proteins do not, therefore, appear to be limiting to growth cone regeneration. Moreover, a simple excess of degradative ability does not prevent regeneration, because inhibiting proteasome activity does not improve regeneration in retinal axons that have the highest levels of degradation machinery and the worst regenerative ability. This contrasts with our findings for the levels of ribosome and initiation factor, which are almost undetectable in those axons that regenerate poorly and that are probably insufficient for the job of making new growth cone proteins.

Although adult retinal axons have almost undetectable levels of protein synthetic machinery, they still showed a little regenerative ability, as did axons treated with protein synthesis inhibi- tors. This suggests that growth cone regeneration can occur in some axons without the local synthesis of proteins, but that its probability is low. Presumably, protein turnover and depolymerization at the site of axotomy can provide sufficient materials for regeneration in these instances.

\section{The conditioning lesion in vitro and in vivo results in axonal changes in protein synthetic machinery}

Peripheral axotomy leads to an increase in the regenerative potential of sensory axons in both the central and peripheral branches. This process, although it requires new protein synthesis, can occur independently of transcription (Smith and Skene, 1997; Twiss et al., 2000). We have cultured conditioned and nonconditioned DRGs, and within the axons that grow out, we find that the conditioning lesion produces an increase in the level of protein synthetic machinery. We see a similar although lesser change in vivo in the sciatic nerve, where there is an increase in the amount of ribosomal-P0 in axons both proximal and distal to the lesion. Again, regenerative ability correlates with levels of synthesis machinery.

Our results suggest that treatments to alter the levels of axonal mRNAs and protein synthesis machinery or to modulate the signaling cascades preceding these processes could provide novel methods for increasing axon regeneration after injury.

\section{References}

Aguayo AJ, Peyronnard JM, Bray GM (1973) A quantitative ultrastructural study of regeneration from isolated proximal stumps of transected unmyelinated nerves. J Neuropathol Exp Neurol 32:256-270.

Baas PW, Luo L (2001) Signaling at the growth cone: the scientific progeny of Cajal meet at Madrid. Neuron 32:981-984.

Baas PW, White LA, Heidemann SR (1987) Microtubule polarity reversal accompanies regrowth of amputated neurites. Proc Natl Acad Sci USA 84:5272-5276.

Bassell GJ, Zhang H, Byrd AL, Femino AM, Singer RH, Taneja KL, Lifshitz LM, Herman IM, Kosik KS (1998) Sorting of $\beta$-actin mRNA and protein to neurites and growth cones in culture. J Neurosci 18:251-265.

Bates CA, Meyer RL (1997) The neurite-promoting effect of laminin is mediated by different mechanisms in embryonic and adult regenerating mouse optic axons in vitro. Dev Biol 181:91-101.

Benfey M, Bunger UR, Vidal-Sanz M, Bray GM, Aguayo AJ (1985) Axonal regeneration from GABAergic neurons in the adult rat thalamus. J Neurocytol 14:279-296.

Black MM, Lasek RJ (1979) Axonal transport of actin: slow component b is the principal source of actin for the axon. Brain Res 171:401-413.

Black MM, Lasek RJ (1980) Slow components of axonal transport: two cytoskeletal networks. J Cell Biol 86:616-623.

Bleher R, Martin R (2001) Ribosomes in the squid giant axon. Neuroscience 107:527-534.

Bray D, Thomas C, Shaw G (1978) Growth cone formation in cultures of sensory neurons. Proc Natl Acad Sci USA 75:5226-5229.

Brittis PA, Lu Q, Flanagan JG (2002) Axonal protein synthesis provides a mechanism for localized regulation at an intermediate target. Cell 110:223-235.

Campbell DS, Holt CE (2001) Chemotropic responses of retinal growth cones mediated by rapid local protein synthesis and degradation. Neuron 32:1013-1026.

Campbell DS, Holt CE (2003) Apoptotic pathway and MAPKs differentially regulate chemotrophic responses of retinal growth cones. Neuron 37:939-952.

Chierzi S, Fawcett JW (2001) Short term reaction of CNS and PNS neurons to in vitro axotomy. Soc Neurosci Abstr 27:366.11.

Dardevet D, Sornet C, Vary T, Grizard J (1996) Phosphatidylinositol 3-kinase and p70 s6 kinase participate in the regulation of protein turnover in skeletal muscle by insulin and insulin-like growth factor I. Endocrinology 137:4087-4094.

Dent EW, Kalil K (2001) Axon branching requires interactions between dynamic microtubules and actin filaments. J Neurosci 21:9757-9769.

Eng H, Lund K, Campenot RB (1999) Synthesis of $\beta$-tubulin, actin, and 
other proteins in axons of sympathetic neurons in compartmented cultures. J Neurosci 19:1-9.

Everett RD (2000) ICPO induces the accumulation of colocalizing conjugated ubiquitin. J Virol 74:9904-10005.

Fernandes KJ, Fan DP, Tsui BJ, Cassar SL, Tetzlaff W (1999) Influence of the axotomy to cell body distance in rat rubrospinal and spinal motoneurons: differential regulation of GAP-43, tubulins, and neurofilament-M. J Comp Neurol 414:495-510.

Forcet C, Stein E, Pays L, Corset V, Llambi F, Tessier-Lavigne M, Mehlen P (2002) Netrin-1-mediated axon outgrowth requires deleted in colorectal cancer-dependent MAPK activation. Nature 417:443-447.

Friede RL, Bischhausen R (1980) The fine structure of stumps of transected nerve fibers in subserial sections. J Neurol Sci 44:181-203.

Fujimuro M, Sawada H, Yokosawa H (1994) Production and characterization of monoclonal antibodies specific to multi-ubiquitin chains of polyubiquitin protein. FEBS Lett 349:173-180.

Gallo G, Letourneau PC (1998) Localized sources of neurotrophins initiate axon collateral sprouting. J Neurosci 18:5403-5414.

Gallo G, Letourneau PC (1999) Different contributions of microtubule dynamics and transport to the growth of axons and collateral sprouts. J Neurosci 19:3860-3873.

Gingras AC, Raught B, Sonenberg N (1999) eIF4 initiation factors: effectors of mRNA recruitment to ribosomes and regulators of translation. Annu Rev Biochem 68:913-963.

Gitler D, Spira ME (1998) Real time imaging of calcium-induced localized proteolytic activity after axotomy and its relation to growth cone formation. Neuron 20:1123-1135.

Goldberg DJ, Wu DY (1995) Inhibition of formation of filopodia after axotomy by inhibitors of protein tyrosine kinases. J Neurobiol 27:553-560.

Goldberg JL, Klassen MP, Hua Y, Barres BA (2002) Amacrine-signaled loss of intrinsic axon growth ability by retinal ganglion cells. Science 296:1860-1864.

Grewal SS, York RD, Stork PJ (1999) Extracellular-signal-regulated kinase signalling in neurones. Curr Opin Neurobiol 9:544-553.

Hanz S, Perlson E, Willis D, Zhang JQ, Massarwa R, Huerta JJ, Kolzenburg M, Kohler M, van-Minnen J, Twiss JL, Fainzilber M (2003) Axoplasmic importins enable retrograde injury signaling in lesioned nerve. Neuron 40:1095-1104.

Herbert TP, Tee AR, Proud CG (2002) The extracellular signal-related kinase pathway regulates the phosphorylation of $4 \mathrm{E}-\mathrm{BP} 1$ at multiple sites. J Biol Chem 277:11591-11596.

Hollenbeck PJ, Bray D (1987) Rapidly transported organelles containing membrane and cytoskeletal components: their relation to axonal growth. J Cell Biol 105:2827-2835.

Koenig E, Giuditta A (1999) Protein-synthesizing machinery in the axon compartment. Neuroscience 89:5-15.

Kulbatski I, Cook DJ, Tator CH (2004) Calcium entry through L-type calcium channels is essential for neurite regeneration in cultures sympathetic neurones. J Neurotrauma 21:357-374.

Lagunowich LA, Schneider JC, Chasen S, Grunwald GB (1992) Immunohistochemical and biochemical analysis of $\mathrm{N}$-cadherin expression during CNS development. J Neurosci Res 32:202-208.

Li D, Field PM, Raisman G (1995) Failure of axon regeneration in postnatal rat entorhinohippocampal slice coculture is due to maturation of the axon, not that of the pathway or target. Eur J Neurosci 7:1164-1171.

McQuarrie IG (1978) The effect of a conditioning lesion on the regeneration of motor axons. Brain Res 152:597-602.

Mendez R, Myers Jr MG, White MF, Rhoads RE (1996) Stimulation of protein synthesis, eukaryotic translation initiation factor $4 \mathrm{E}$ phosphoryla- tion, and PHAS-I phosphorylation by insulin requires insulin receptor substrate 1 and phosphatidylinositol 3-kinase. Mol Cell Biol 16:2857-2864.

Ming GL, Wong ST, Henley J, Yuan XB, Song HJ, Spritzer NC, Poo MM (2002) Adaptation in the chemotactic guidance of nerve growth cones. Nature 417:411-418.

Neumann S, WoolfCJ (1999) Regeneration of dorsal column fibers into and beyond the lesion site following adult spinal cord injury. Neuron 23:83-91.

Olink-Coux M, Hollenbeck PJ (1996) Localization and active transport of mRNA in axons of sympathetic neurons in culture. J Neurosci 16:1346-1358.

Pan YA, Misgeld T, Litchman JW, Sanes JR (2003) Effects of neurotoxic and neuroprotective agents on peripheral nerve regeneration assayed by timelapse imaging in vivo. J Neurosci 23:11479-11488.

Perron JC, Bixby JL (1999) Distinct neurite outgrowth signaling pathways converge on ERK activation. Mol Cell Neurosci 13:362-378.

Rehder V, Jensen JR, Kater SB (1992) The initial stages of neural regeneration are dependent upon intracellular calcium levels. Neuroscience 51:565-574.

Rossi F, Jankovski A, Sotelo C (1995) Differential regenerative response of Purkinje cell and inferior olivary axons confronted with embryonic grafts: environmental cues versus intrinsic neuronal determinants. J Comp Neurol 359:663-677.

Rossi F, Buffo A, Strata P (2001) Regulation of intrinsic regenerative properties and axonal plasticity in cerebellar Purkinje cells. Restor Neurol Neurosci 19:85-94.

Shaw G, Bray D (1977) Movement and extension of isolated growth cones. Exp Cell Res 104:55-62.

Shewan D, Dwivedy A, Anderson R, Holt CE (2002) Age-related changes underlie switch in netrin-1 responsiveness as growth cones advance along visual pathway. Nat Neurosci 5:955-962.

Smith DS, Skene JH (1997) A transcription-dependent switch controls competence of adult neurons for distinct modes of axon growth. J Neurosci 17:646-658.

Sonenberg N, Gringras AC (1998) The mRNA 5' cap-binding protein eIF and control of cell growth. Curr Opin Cell Biol 10:267-275.

Spira ME, Oren R, Dormann A, Gitler D (2003) Critical calpain-dependent ultrastructural alterations underlie the transformation of an axonal segment into a growth cone after axotomy of cultured Aplysia neurons. J Comp Neurol 457:293-312.

Tetzlaff W, Kobayashi NR, Giehl KM, Tsui BJ, Cassar SL, Bedard AM (1994) Response of rubrospinal and corticospinal neurons to injury and neurotrophins. Prog Brain Res 103:271-286.

Twiss JL, Smith DS, Chang B, Shooter EM (2000) Translational control of ribosomal protein L4 mRNA is required for rapid neurite regeneration. Neurobiol Dis 7:416-428.

Vidal-Sanz M, Bray GM, Villegas-Perez MP, Thanos S, Aguayo AJ (1987) Axonal regeneration and synapse formation in the superior colliculus by retinal ganglion cells in the adult rat. J Neurosci 7:2894-2909.

Wessells NK, Johnson SR, Nuttall RP (1978) Axon initiation and growth cone regeneration in cultured motor neurons. Exp Cell Res 117:335-345.

Zheng JQ, Kelly TK, Chang B, Ryanzantsev S, Rajasekaran AK, Martin KC, Twiss JL (2001) A functional role for intra-axonal protein synthesis during axonal regeneration from adult sensory neurons. J Neurosci 21:9291-9303.

Ziv NE, Spira ME (1998) Induction of growth cone formation by transient and localised increases of intracellular proteolytic activity. J Cell Biol 140: 223-232. 